\title{
A Polyvinyl Alcohol-Polyaniline Based Electro-Conductive Hydrogel for Controlled Stimuli-Actuable Release of Indomethacin
}

\section{Tong-Sheng Tsai ${ }^{1}$, Viness Pillay ${ }^{1}{ }^{*}$, Yahya E. Choonara ${ }^{1}$, Lisa C. du Toit ${ }^{1}$, Girish Modi ${ }^{2}$, Dinesh Naidoo ${ }^{3}$ and Pradeep Kumar ${ }^{1}$}

1 Department of Pharmacy and Pharmacology, University of the Witwatersrand, 7 York Road, Parktown, 2193, Johannesburg, South Africa; E-Mails: tong-sheng.tsai@students.wits.ac.za (T.-S.T.); yahya.choonara@wits.ac.za (Y.E.C.); lisa.dutoit@wits.ac.za (L.C.T.); pradeep.kumar@students.wits.ac.za (P.K.)

2 Division of Neurosciences, Department of Neurology, University of the Witwatersrand, Johannesburg, South Africa; E-Mail: gmodicns@mweb.co.za (G.M.)

3 Division of Neurosciences, Department of Neurosurgery, University of the Witwatersrand, Johannesburg, South Africa; E-Mail: dineshnaidoo@yahoo.com (D.N.)

* Author to whom correspondence should be addressed; E-Mail: viness.pillay@wits.ac.za; Tel.: +27-11-717-2274; Fax: +27-86-553-4733.

Received: 8 November 2010; in revised form: 1 December 2010 / Accepted: 29 December 2010 / Published: 5 January 2011

\begin{abstract}
Electro-conductive hydrogels based on poly(vinyl alcohol), crosslinked with diethyl acetamidomalonate as the hydrogel component, were engineered using polyaniline as the inherently conductive component, and fabricated in the form of cylindrical devices to confer electro-actuable release of the model drug indomethacin. The hydrogels were characterized for their physicochemical and physicomechanical properties. Cyclic voltammetry was employed for electro-activity and conductivity analysis. Drug entrapment efficiency ranged from 65-70\%. "ON-OFF" switchable drug release was obtained by periodically applying-removing-reapplying an electric potential ranging from $0.3-5.0 \mathrm{~V}$ for 60 seconds at hourly intervals and the cumulative drug release obtained ranged from $4.7-25.2 \%$ after four release cycles respectively. The electro-stimulated release of indomethacin was associated with the degree of crosslinking, the polymeric ratio and drug content. A Box-Behnken experimental design was constructed employing $1.2 \mathrm{~V}$ as the baseline potential difference. The devices demonstrated superior swellability and high
\end{abstract}


diffusivity of indomethacin, in addition to high electrical conductivity with "ON-OFF" drug release kinetics via electrical switching. In order to investigate the electro-actuable release of indomethacin, molecular mechanics simulations using AMBER-force field were performed on systems containing water molecules and the poly(vinyl alcohol)-polyaniline composite under the influence of an external electric field. Various interaction energies were monitored to visualize the effect of the external electric field on the erosion of polyaniline from the co-polymeric matrix. This strategy allows the electro-conductive hydrogels to be suitably applied for controlled, local and electro-actuable drug release while sustaining a mild operating environment.

Keywords: electro-conductive hydrogels; indomethacin; polyaniline; poly(vinyl alcohol); controlled drug release; cyclic voltammetry; matrix erosion; morphological analysis

\section{Introduction}

Stimuli responsive hydrogels are three dimensional systems composed of a solid crosslinked matrix network and interstitial fluid with or without ionic species [1]. Several responsive hydrogels such as $\mathrm{pH}[2,3]$, temperature [4,5] and enzyme [6,7] stimulated systems are currently under research. However, substance release from these responsive hydrogels mostly relies on internal stimulus for activation and cannot be controlled. Electro-conductive hydrogels (ECHs), with electrically tunable properties, primarily consist of an inherently conducting polymer within a tridimensional crosslinked network of a polymer-based hydrogel. The combination of conductive properties of electro-active polymers (EAPs) and the swelling/de-swelling capabilities of the hydrogel, make them dynamic and versatile for various biomedical purposes [8], such as implantable drug delivery systems, thus allowing for patient-controlled release of drugs at the times of need directly into the target area.

There are various EAPs which may be used as conducting polymers, such as polypyrrole $[9,10]$, polythiophene [11,12], poly(3,4-ethylenedioxythiophene) (PEDOT) [13] and polyaniline (PANi) [14]. Among these, the application of PANi as an EAP has attracted much attention in a wide variety of fields such as artificial muscles [15,16], technological applications such as rechargeable batteries, electromagnetic interference shielding, microwave and radar absorbing materials, anti-static and anti-corrosive coatings [17,18], biosensors [19] and conducting polymers [20]. This is attributed to the simplicity of its synthesis, either chemically or electrochemically, high degree of chemical stability and easy doping process [21]. PANi, the inherently conductive polymer, has also been shown to be biocompatible and is therefore the EAP of choice for the synthesis of Electro-Conductive Hydrogel (ECH) [22-25]. When EAPs such as PANi or polypyrrole (PPy) are used alone, they display a lack of solubility and fragility, thus requiring the blending of the EAP into a co-matrix system making it an essential step for the synthesis of the ECH [26]. The preparation of a hydrogel can be performed by either using a natural or a synthetic polymer [27]. Synthetic polymers are usually preferred since natural polymers, although more biocompatible, may not have sufficient mechanical strength and may cause inflammation due to contamination from pathogens [28]. Synthetic polymers, on the other hand, 
can be tailored to suit individual needs in terms of functionality. The use of a synthetic polymer as a drug delivery system generally causes concern regarding its biocompatibility. With the myriads of synthetic polymers being discovered, several with the potential to be used in a drug delivery system have been investigated regarding their biocompatibility. Although not all, some EAPs with favorable characteristics such as the PANi-derivatives and the PPy-derivatives have also shown to be biocompatible. Those non-biocompatible are required to be re-modified or otherwise be utilized as an ex vivo drug delivery system where there is no risk of causing any untoward reactions in the patients. Polymers such as polyacrylic acid [29], polyacrylamide [30], polysaccharides [31], poly( $N$-isopropyl acrylamide) [32] and poly(vinyl alcohol) (PVA) [30,31] all have potential for the synthesis of a hydrogel. PVA was selected as the hydrogel component in this study based on its favorable water-soluble, desirable physicochemical properties and its biocompatibility [33]. Furthermore, chemically crosslinked PVA hydrogel has been gaining increasing attention in the field of biomedics [34].

This study focused on developing an ECH that is capable of electro-actuable release of the model drug indomethacin in the presence of an electric field by co-blending PANi with PVA and subsequently crosslinking with diethyl acetamidomalonate (DAA), as a polymeric hydrogel system. The diethyl group of DAA, a biocompatible crosslinking agent [35], renders it chemically reactive and was responsible for the crosslinking action [36]. A hydrogel may be synthesized as a blend, a copolymer, a graft copolymer, an interpenetrating polymer network (IPN) or a composite and each is structured differently. A blend hydrogel is one which is synthesized by interaction between two or more reagents. One example would be a hydrogel formed via the esterification of PVA and gelatine [37]. The esterification occurs between the hydroxyl group of the PVA and the carboxyl group of the gelatine, thus resulting in the hydrogel. Sometimes, the hydrogel may be as a result of two monomers reacting together to form a polymer, or by incorporation of one polymer into another. These hydrogels are termed co-polymer hydrogels. A study done by Henderson and co-workers has managed to form a hydrogel consisting of a crosslinked tri-block copolymer network [38]. A graft copolymeric hydrogel is similar to a copolymer hydrogel, as the polymer which is used to form the hydrogel is a graft co-polymer [39]. A graft copolymer is a type of branched copolymer with the side chain being different and separate from the main chain. As in the case of the graft copolymer, the copolymer formed usually combines the properties of both polymers which forms the copolymer [40].

The next hydrogel structure which may be formed is the IPN, which is essentially a network of a component within the hydrogel network itself. It may be classified as a class of polymer blends in network form, in which at least one component is polymerized in the presence of the other [41]. EAPs are commonly incorporated into the hydrogel in the form of IPN. This may increase the conductivity of the electrical stimulation into the hydrogel and thus improve the electro-response of the hydrogel. The IPN hydrogel may be formed by initially creating a solution containing both components. The initiator and crosslinker is then added into the solution simultaneously. The crosslinking and polymerization is then allowed to continue for several hours until the hydrogel is formed [42]. IPN hydrogel is commonly synthesized with an EAP incorporated.

The last class of hydrogel is the composite hydrogel. A composite hydrogel is formed with a particle being embedded within the hydrogel network. These particles do not have any direct interactions with the hydrogel. Composite hydrogels can be synthesized as a responsive hydrogel, 
where the drug was entrapped within the hydrogel. The responsive hydrogel then swells/deswells when exposed to various stimuli and thus results in drug release [43]. One more important reason for using DAA as a crosslinker is that it offers adequate structural integrity of the $\mathrm{ECH}$ without compromising its swelling capability. Indomethacin was incorporated into the ECH as the model drug for controlled release via electro-actuation. Indomethacin is used for the treatment of chronic pain and it is well known that repeated oral dosing of indomethacin causes undesirable side-effects such as gastric irritation [44-46]. Therefore, the incorporation of indomethacin into the ECH may allow for the controlled release of indomethacin in the targeted area, thus reducing side-effects. This work investigated the effect of electric-actuation of drug release from the ECH in addition to characterization studies.

\section{Results and Discussion}

A novel conductive polymer composite prepared as an Electro-Conductive Hydrogel (ECH) constituting a water-dispersed complex of polyaniline embedded in a diethyl acetamidomalonate (DAA) crosslinked polyvinyl alcohol (PVA) hydrogel was evaluated as a matrix for electro-actuable release of the model drug indomethacin as a long-term site-specific drug delivery system.

\subsection{Optimization of Electro-Conductive Hydrogel}

The preparation of the ECH was based on the optimized values obtained from a Box-Behnken experimental design. The optimized values of the formulation variables were obtained by measuring the drug release profile, Drug Entrapment Efficiency (DEE) and erosion rate of the ECH. The aim of this design was to obtain an ECH with constraints set at a drug release of approximately $1.7 \%$ of the total drug per release cycle, maximum DEE and minimum erosion. Results obtained using Minitab ${ }^{\circledR}$ V15 (Minitab ${ }^{\circledR}$, State College, PA, U.S.) software approximations are shown in Tables 1 and 2.

Table 1. Box-Behnken guided variables and observed responses for the ECH formulations.

\begin{tabular}{lccccccccc}
\hline Batch & \multicolumn{3}{c}{ Independent variables } & \multicolumn{3}{c}{ Dependent variables } & \multicolumn{2}{c}{ Levels, Actual (Coded) } \\
\hline & $\begin{array}{c}\text { PANi } \\
(\% \mathrm{w} / \mathrm{w})\end{array}$ & $\begin{array}{c}\text { PVA } \\
(\mathrm{g})\end{array}$ & $\begin{array}{c}\text { DAA } \\
(\mathrm{g})\end{array}$ & $\begin{array}{c}\text { Drug Release } \\
(\%)\end{array}$ & $\begin{array}{c}\text { DEE } \\
(\%)\end{array}$ & $\begin{array}{c}\text { Erosion } \\
(\% \mathrm{w} / \mathrm{w})\end{array}$ & $\begin{array}{c}\text { Low } \\
(-1)\end{array}$ & $\begin{array}{c}\text { Medium } \\
(0)\end{array}$ & $\begin{array}{c}\text { High } \\
(1)\end{array}$ \\
\hline 1 & -1 & 1 & 0 & 1.9 & 89.44 & 5.5 & & & \\
2 & 1 & 0 & 1 & 12.0 & 37.89 & 17.32 & & & \\
3 & -1 & 0 & 1 & 18.0 & 43.18 & 10.43 & & & \\
$4^{\mathrm{a}}$ & 0 & 0 & 0 & 24.0 & 36.62 & 14.16 & & \\
5 & 0 & 1 & -1 & 16.0 & 39.74 & 8.97 & & \\
6 & 1 & 1 & 0 & 11.0 & 59.22 & 7.36 & & \\
7 & -1 & 0 & -1 & 5.9 & 73.67 & 5.67 & & \\
$8^{\mathrm{a}}$ & 0 & 0 & 0 & 57.0 & 23.87 & 4.28 & & \\
9 & 0 & -1 & -1 & 12.0 & 82.02 & 15.91 & & \\
10 & 1 & -1 & 0 & 7.7 & 82.43 & 23.39 & & \\
11 & 0 & -1 & 1 & 15.8 & 41.95 & 8.77 & & \\
$12^{\mathrm{a}}$ & 0 & 0 & 0 & 24.4 & 36.07 & 24.36 & & & \\
13 & 0 & 1 & 1 & 42.0 & 34.25 & 9.05 & & & \\
14 & -1 & -1 & 0 & 41.0 & 25.07 & 15.31 & & & \\
15 & 1 & 0 & -1 & 34.0 & 26.63 & 10.16 & & & \\
\hline
\end{tabular}


Table 1. Cont.

\begin{tabular}{|c|c|c|c|c|c|c|c|c|c|}
\hline \multirow[t]{2}{*}{ Batch } & \multicolumn{3}{|c|}{ Independent variables } & \multicolumn{3}{|c|}{ Dependent variables } & \multicolumn{3}{|c|}{ Levels, Actual (Coded) } \\
\hline & $\begin{array}{l}\text { PANi } \\
(\% \mathrm{w} / \mathrm{w})\end{array}$ & $\begin{array}{l}\text { PVA } \\
(\mathrm{g})\end{array}$ & $\begin{array}{l}\text { DAA } \\
(\mathrm{g})\end{array}$ & $\begin{array}{c}\text { Drug Release } \\
(\%) \\
\end{array}$ & $\begin{array}{c}\text { DEE } \\
(\%) \\
\end{array}$ & $\begin{array}{l}\text { Erosion } \\
(\% \mathrm{w} / \mathrm{w})\end{array}$ & $\begin{array}{l}\text { Low } \\
(-1)\end{array}$ & $\begin{array}{c}\text { Medium } \\
(0)\end{array}$ & $\begin{array}{l}\text { High } \\
(1)\end{array}$ \\
\hline \multicolumn{10}{|c|}{ Independent variables } \\
\hline \multicolumn{4}{|c|}{ PVA (g) } & & & & 0.50 & 0.65 & 0.80 \\
\hline \multicolumn{4}{|c|}{ DAA (g) } & & & & 0.00 & 0.15 & 0.30 \\
\hline \multicolumn{4}{|c|}{ PANi $(\% \mathrm{w} / \mathrm{w})$} & & & & 1.0 & 2.5 & 4.0 \\
\hline
\end{tabular}

Table 2. Composition of optimized ECH formulation.

\begin{tabular}{lccc}
\hline Constraints set & $\begin{array}{c}\text { Drug Release } \\
(\mathbf{\%})\end{array}$ & $\begin{array}{c}\text { DEE } \\
(\mathbf{\%})\end{array}$ & $\begin{array}{c}\text { Erosion rate } \\
(\mathbf{\%})\end{array}$ \\
\hline Target & 1.7 & Maximized & Minimized \\
Yield & 1.9040 & 80.5381 & 6.3201 \\
$\mathrm{~d}^{*}$ & 0.99993 & 0.87179 & 0.93052
\end{tabular}

Optimal $=$ PANi $(1.3418 \%$ w/w $)$, PVA $(0.8 \mathrm{~g})$, DAA $(0.0689 \mathrm{~g}) ; \mathrm{D}^{* *}=0.93261$

$* \mathrm{~d}=$ Probability of obtaining the yield value when using the generated optimized values; **D $=$ Probability of the ECH having the indicated yield value for drug release, DEE and erosion rate.

The optimized ECH formulation was prepared using $0.8 \mathrm{~g}$ of PVA crosslinked with $0.0689 \mathrm{~g}$ of DAA with $1.3418 \% \mathrm{w} /{ }_{\mathrm{w}}$ of PANi, incorporated in order to exhibit a probability of 0.93261 of achieving the desired yield value (Table 2). The quantity of indomethacin used for the formulation was kept constant at $100 \mathrm{mg}$ and the crosslinking agent used was approximately $8.5 \%$ of the PVA incorporated, as computed during software-assisted optimization.

\subsection{Assessment of the Surface Morphology of the ECH}

The eroded portions of the ECH were visualized using light microscopy to compare the morphological differences with that of the non-eroded regions, in addition to observing the effects of PANi concentrations on the appearance of the ECH, as depicted in Figures 1(a-d). Scanning electron microscopy (SEM) was used to examine whether the hydrogel erosion followed a surface phenomenon or if it extended deeper into the hydrogel structure (surface erosion or bulk erosion) of the $\mathrm{ECH}$, as shown in Figures 1(e) and 1(f).

As evidenced from Figures 1(a) and 1(b), the color of the PANi-hydrogel at the erosion site was more obvious due to the decrease in PANi as a consequence of hydrolytic erosion, since PANi provided the distinctive dark color to the hydrogel system. It is therefore possible to link PANi to the erosion dynamics that occurred at these sites. ECHs prepared without PANi did not undergo any erosion when exposed to electrical stimulation, thus strongly suggesting that the interaction occurred between the PANi and the anode [figures not shown]. A close microscopical investigation of $3 \% \mathrm{w} / \mathrm{w}$ 
and $1 \% \mathrm{w} / \mathrm{w}$ ECHs revealed that the $3 \% \mathrm{w} / \mathrm{w}$ ECH was distinctively darker as observed in Figures 1(c) and 1(d), respectively. The PANi can be seen as isolated black spots that suggested they were not inter-connected, and thus any erosion that occurred appears to be a surface phenomenon and may not extend beyond the surface. Furthermore, erosion studies performed on ECHs containing different concentrations of PANi revealed that the PANi-hydrogel system with a $3 \% \mathrm{w} /{ }_{\mathrm{w}}$ PANi exhibited a significantly higher erosion rate than that of a $1 \% \mathrm{w} / \mathrm{w}$ PANi-hydrogel system, as discussed further in Section 2.5.

Figure 1. Light micrographs of the $\mathrm{ECH}$ showing: (a) and (b) eroded sites of the $\mathrm{ECH}$ (highlighted in red) $(\times 32)$; (c) $3 \% \mathrm{w} / \mathrm{w}$ PANi $(\times 32)$; (d) $1 \% \mathrm{w} / \mathrm{w}$ PANi $(\times 32)$ and SEM micrographs of the ECH showing: $(\mathbf{e})$ the non-eroded region $(\times 350)$ and $(\mathbf{f})$ the eroded region $(\times 390)$.

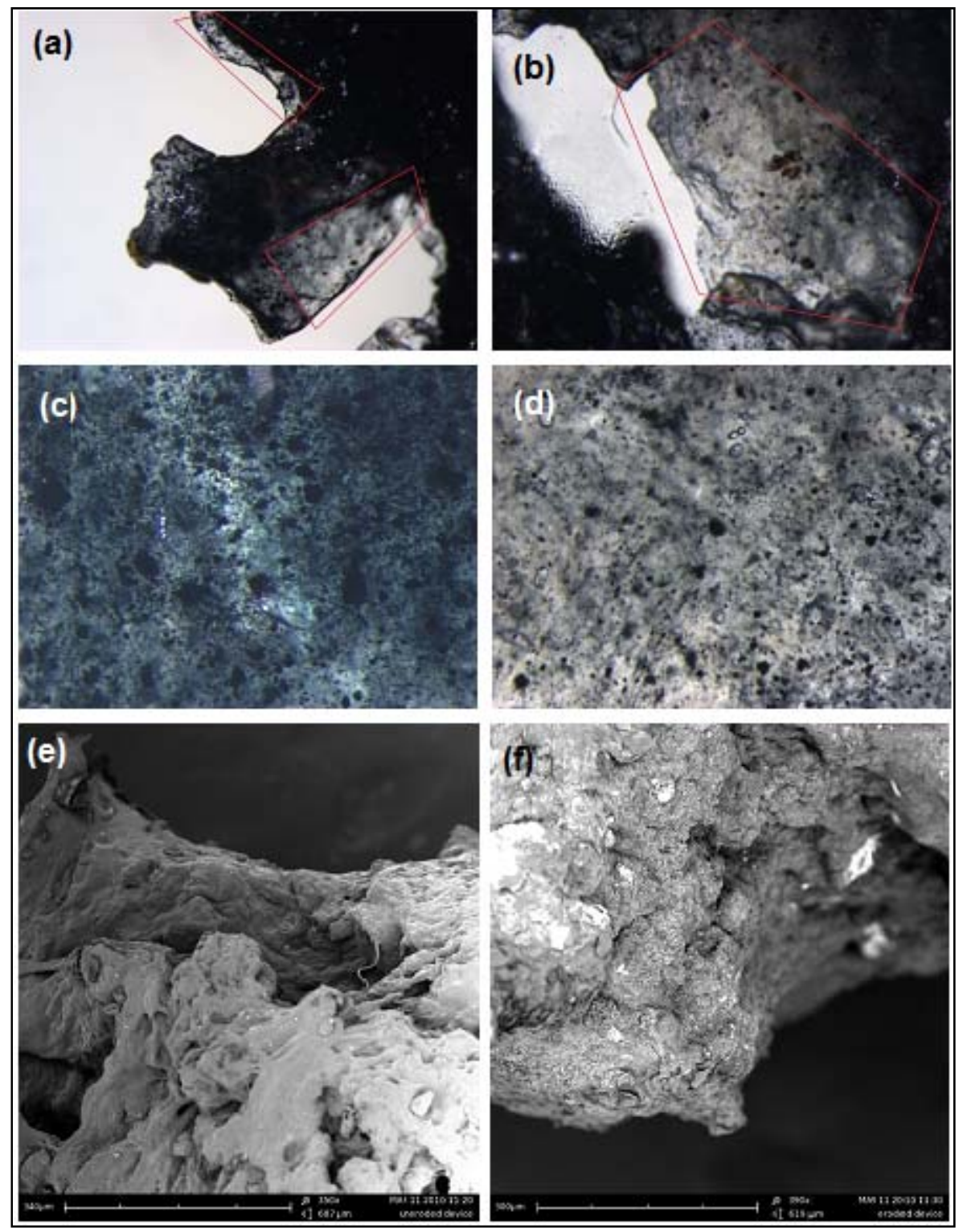

The surface morphology was further assessed using SEM. The samples were initially coated with a gold coating for a period of 90 seconds before loading onto a SEM in order to enhance the image 
resolution. The magnifications of the samples were approximately 300-400×. SEM images were taken from an eroded site and a non-eroded site on the same $\mathrm{ECH}$, for comparison of any changes in the surface morphology before and after the erosion, and to assess the extent of erosion. SEM images of the non-eroded and eroded regions of the ECH are depicted in Figures 1(e) and 1(f), respectively. The difference in texture is evident from the micrographs. The ECH originally presented with a relatively smooth surface morphology (Figure 1(e)). When particle erosion proceeded, small portions of the ECH flaked off the surface, thus leaving the surface uneven as depicted in Figure 1(f). Additionally, it is evident from Figure 1(f) that erosion occurred only on the surface and did not extend further into the bulk of the $\mathrm{ECH}$.

\subsection{Effect of Crosslinking on the Rate of Erosion of the ECH}

To determine the effect of the quantity of PVA and DAA on the erosion of the ECH system, five ECH systems with varying constituents were synthesized and exposed to electric current (Table 2). Each system was fabricated with $20 \mathrm{mg}$ PANi, but the quantity of PVA and DAA were varied from $0.25-1.0 \mathrm{~g}$ and $0.0-1.0 \mathrm{~g}$, respectively.

Each system (F1-F5) were immersed in $25 \mathrm{~mL}$ of phosphate-buffered saline (PBS) and exposed to $1.2 \mathrm{~V}$ of potential difference for 10 minutes. The formulations were then assessed for their extent of erosion and thus the effect of PVA and DAA on the hydrogel system was evaluated. Results revealed that F1 (14\%) and F5 (11\%) had higher erosion rates compared to the minimal erosion rates of $\mathrm{F} 2(4 \%), \mathrm{F} 3(6 \%)$ and F4 (7\%), with F2 having the lowest erosion rate.

The erosion rate was observed to be dependent on two factors: The degree of crosslinking and the concentration of PANi in the hydrogel. The lesser the degree of crosslinking and the higher the concentration of PANi, the higher was the rate of erosion (Table 3). Generally, crosslinking increases the structural integrity of the polymer matrix, thus decreasing the erosion rate [47-49]. The water uptake also decreases, and thus the swelling, owing to the formation of the rigid structure which ultimately affects the transport of ions across the hydrogel [50]. Regarding the synthesis of the $\mathrm{ECH}$, while the addition of PVA forms a loosely bound hydrogel network, the addition of DAA resulted in a rigid crosslinked network. In F1, there was no crosslinking between the polymeric chains of PVA due to the absence of the DAA, resulting in a loose network allowing the erosion of PANi in a concentration dependent manner. In addition, the higher mass percentage of PANi resulted in a higher rate of erosion. In the case of F2, the quantity of DAA was increased to twice that of PVA, which resulted in a highly dense rigid network structure as compared to F1. The mass percentage of the PANi in the hydrogel system was, furthermore, the lowest as compared to the other formulations resulting in the lowest percentage erosion. In the case of F3, having the same degree of crosslinking compared to F2, the lower quantity of PVA and DAA employed decreased the total hydrogel volume making the PANi mass percentage to rise to $2.59 \%$. The percentage erosion of F3 was thus similar but slightly higher than that of F2. Formulation F4 was similar to F2, except that the quantity of the DAA and PVA used were switched. F2 was DAA dominant, which resulted in a rigid network, whereas F4 was PVA dominant thereby forming a loose network. Although they both possessed the identical PANi concentration, F4 had a loosely crosslinked network and thus exhibited higher erosion when compared to F2. Formulation F5 demonstrated a higher erosion rate compared to F2, F3 and F4 because, similar 
to F4, the PVA was dominant over DAA, thus forming a loosely crosslinked network. Furthermore, the quantity of PVA used was lower compare to F4, thus resulting in a higher PANi mass percentage. The concentration of PANi was, however, not higher than that of F1. Therefore, although it exhibited higher erosion compared to F2, F3 and F4, it was still lower than that of F1.

Table 3. Formulation template employed for preparing each ECH system.

\begin{tabular}{lcccc}
\hline Formulation & $\begin{array}{c}\text { DAA } \\
\text { g (\%) }\end{array}$ & $\begin{array}{c}\text { PVA } \\
\text { g (\%) }\end{array}$ & $\begin{array}{c}\text { PANi } \\
\text { mg (\%) }\end{array}$ & $\begin{array}{c}\text { Erosion } \\
\text { \% of original mass }\end{array}$ \\
\hline F1 & $0.0(0.0)$ & $0.5(96.15)$ & $20(3.85)$ & 14 \\
F2 & $1.0(65.79)$ & $0.5(32.89)$ & $20(1.32)$ & 4 \\
F3 & $0.5(64.94)$ & $0.25(32.47)$ & $20(2.59)$ & 6 \\
F4 & $0.5(32.89)$ & $1.0(65.79)$ & $20(1.32)$ & 7 \\
F5 & $0.25(32.47)$ & $0.5(64.94)$ & $20(2.59)$ & 11 \\
\hline
\end{tabular}

\subsection{Voltage Optimization Based on the Drug Release Profile from the ECH}

ECH formulations were synthesized and immersed in $20 \mathrm{~mL}$ of PBS (pH 7.4; $\left.37{ }^{\circ} \mathrm{C}\right)$. A $5 \mathrm{~mm}$ platinum electrode was used as the cathode and a $5 \mathrm{~mm}$ gold electrode was used as the anode. The two electrodes were placed directly on the $\mathrm{ECH}$ and a potential difference was maintained between the two electrodes. In this study, six ECH formulations were synthesized and a potential difference ranging from $0.3 \mathrm{~V}, 1.2 \mathrm{~V}, 2 \mathrm{~V}, 3 \mathrm{~V}, 4 \mathrm{~V}$ and $5 \mathrm{~V}$ was applied to each formulation respectively using a potentiostat/galvanostat (PGSTAT302N, Autolab, Utrecht, Netherlands). The potential difference was maintained for one minute and $2 \mathrm{~mL}$ PBS was sampled hourly with replacement of fresh PBS medium after the application of the electrical stimulation to maintain sink conditions. The same procedure was performed for up to four release cycles and samples were analyzed for indomethacin content using UV/visible spectroscopy (Lambda 25 UV/Vis Spectroscopy, Perkin-Elmer, Shelton, CT, U.S.). The resultant drug release profiles obtained are shown in Figure 2.

Figure 2. Drug release profiles showing the influence of various potential differences on the ECH.

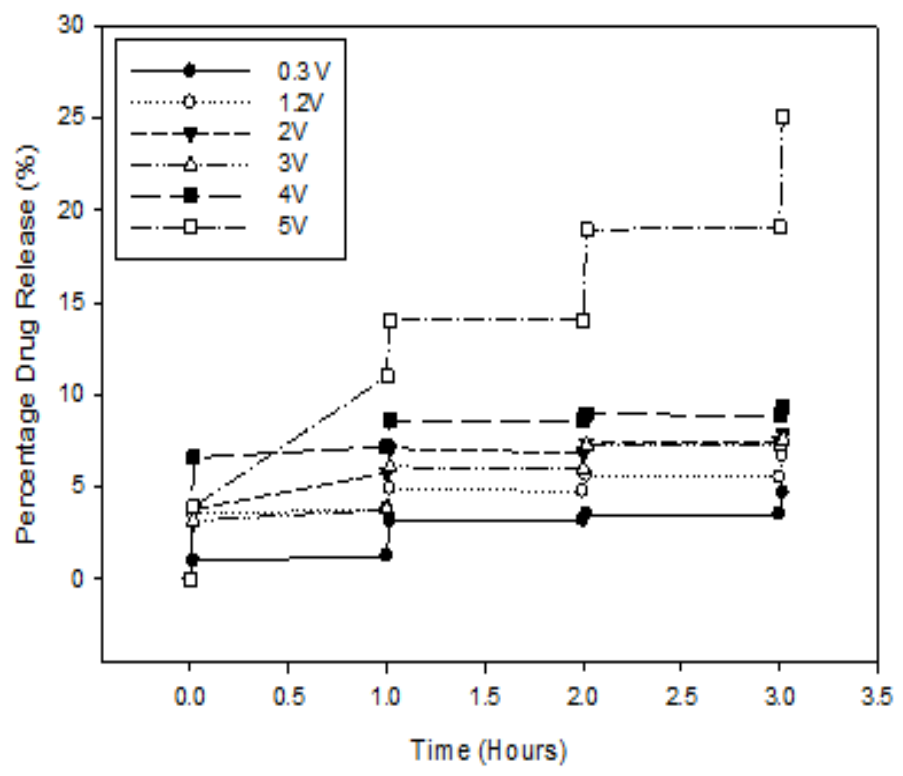


It was deduced from Figure 2 that drug release from the ECH increased with an increase in the potential difference applied, although not in a linear order. In some instances, drug was released in between the hourly stimulation, as observed in the first hour with a $5 \mathrm{~V}$ potential application. The leaching of drug around the erosion site may occur at random due to drug adsorbed at the surface. However, further data indicated that this leaching did not occur further on in the release cycle. Therefore, it can be implied that it was possible to achieve controlled release of therapeutic dose of indomethacin at specific intervals by selecting an optimal potential difference. A high fractional drug release from the ECH would render the system unfavorable and require frequent replacement. By using the fractional drug release obtained after four cycles, the maximum quantity of drug release possible under different voltage stimulations was computed as depicted in Figure 3. The number of drug release cycles achievable seems fairly constant between potential differences of 1.5-3.5 V (Figure 3), as the fractional drug release does not seem to deviate by much. Fractional drug release, however, changed significantly when the potential difference was set outside this range.

Figure 3. Profile showing the number of release cycles obtainable from the ECH at a specified applied voltage.

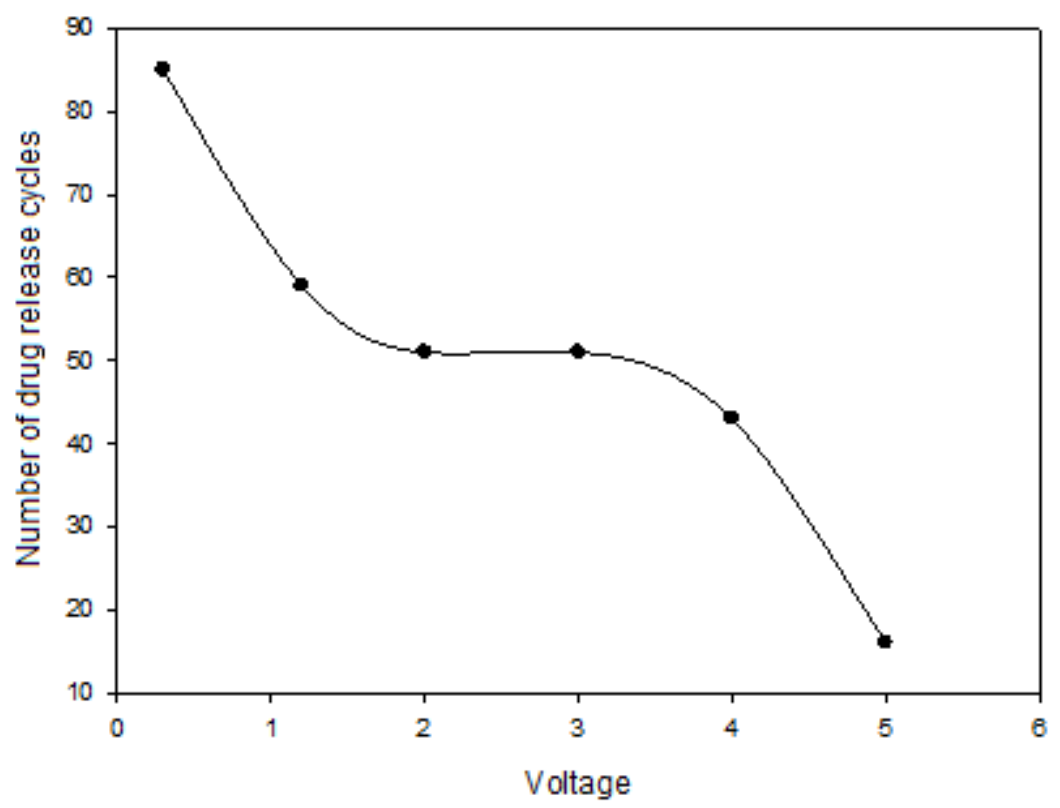

Results obtained from Figure 3 revealed that the application of $1.2 \mathrm{~V}$ to the ECH may allow approximately 60 release cycles, with an average of $1.15 \mathrm{mg}$ indomethacin liberated per release cycle. This corresponds to adequate release of indomethacin for 60 release cycle. The $1.2 \mathrm{~V}$, application of $0.3 \mathrm{~V}$ resulted in approximately $0.77 \mathrm{mg}$ drug release for 80 release cycles. The number of release cycles dropped to around 50 when the potential difference was increased from 2-3 V with an average of $1.41 \mathrm{mg}$ indomethacin per release cycle, whereas the number of release cycles dropped to $<20$ with an average of $4.39 \mathrm{mg}$ per release cycle for a $5 \mathrm{~V}$ potential difference. Based on these results, $1.2 \mathrm{~V}$ was selected as the optimum potential difference to be applied to the ECH as it may allow approximately a one month supply of twice-daily controlled release of adequate quantities of indomethacin. 


\subsection{The Rate of Erosion as a Mechanism for Drug Release from the ECH}

When a potential difference of $1.2 \mathrm{~V}$ was applied to the $\mathrm{ECH}$, erosion was evident on the surface of the $\mathrm{ECH}$ and repeated application of electrical stimulation further eroded the ECH. The extent of erosion decreased with an increase in the degree of crosslinking, due to strengthening of the structural integrity of the ECH [47-49]. However, an increase in PANi also led to an increase in erosion which suggested that PANi played a key role in the erosion process of the ECH. Figures 4(a) and 4(b) demonstrates a comparison between the $\mathrm{ECH}$ before and after exposure to electrical stimulation.

Figure 4. Digital images showing the $\mathrm{ECH}$ (a) before electrical stimulation and (b) after 30 release cycles.
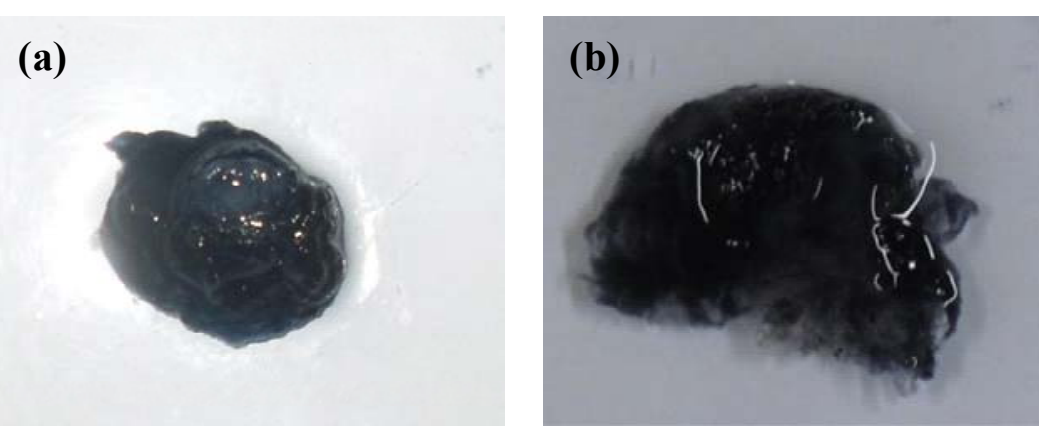

Figure 4(b) depicts an ECH formulation which eroded after 30 release cycles. The erosion tended to progress until complete disintegration of the ECH occurred. However, drug from the ECH may be depleted completely by the end of that stage. The erosion mainly occurred at the anode and was negligible at the cathode, suggesting a possible interaction occurring between the anode and the ECH. Table 4 demonstrates the results obtained for the erosion study performed on two ECH formulations comprising $1 \% \mathrm{w} / \mathrm{w}$ and $3 \% \mathrm{w} / \mathrm{w}$ PANi, respectively. The increase in erosion due to an increase in PANi led to the assumption that an interaction between PANi and the hydrogel occurred during electro-actuation leading to erosion. This may be due to the formation of a positively charged quaternary ammonium group on the aniline during the formation of the $\mathrm{ECH}$ and the acidic properties of the acetone resulting in protonation of the PANi (Figure 5). This positively charged quaternary ammonium group appeared to be attracted toward the anode, thereby creating a void in the hydrogel structure resulting in weakening of the ECH structure and subsequent erosion. Drug migrated towards the electrode during weakening in the hydrogel structure, thus resulting in drug release through the voids. The weakening of the ECH and the subsequent migration of drug ceased when the electrical current was halted (surface erosion as discussed earlier). Any drug within the ECH near the erosion site may still diffuse outward of the ECH due to weakening of the structure around the erosion site. This may explain the minimal quantity of indomethacin released after the electrical stimulation ceased. The detailed schematics of the mechanism of erosion and drug release are depicted in Figures 5 and 6, respectively.

Table 4. Erosion rate data of ECH containing varying concentrations of PANi.

\begin{tabular}{cc}
\hline PANi concentration & Erosion rate (\% of original mass) \\
\hline $1 \% \mathrm{w} / \mathrm{w}$ & 4.23 \\
$3 \% \mathrm{w} / \mathrm{w}$ & 10.43 \\
\hline
\end{tabular}


Figure 5. The mechanism of ECH erosion as observed via interactive chemical reactivity.

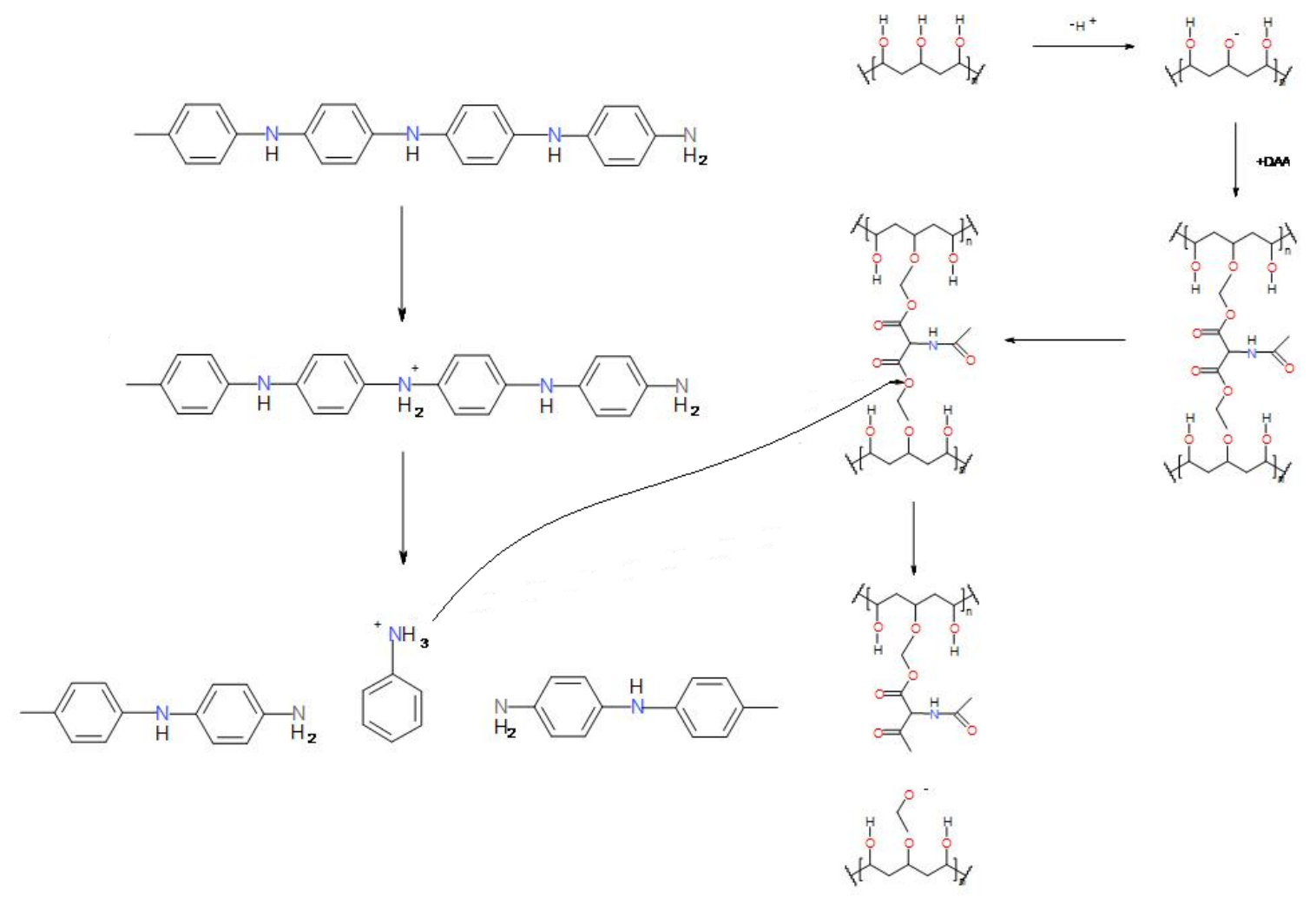

Figure 6. Schematic depicting the potential mechanism of drug release from the ECH.
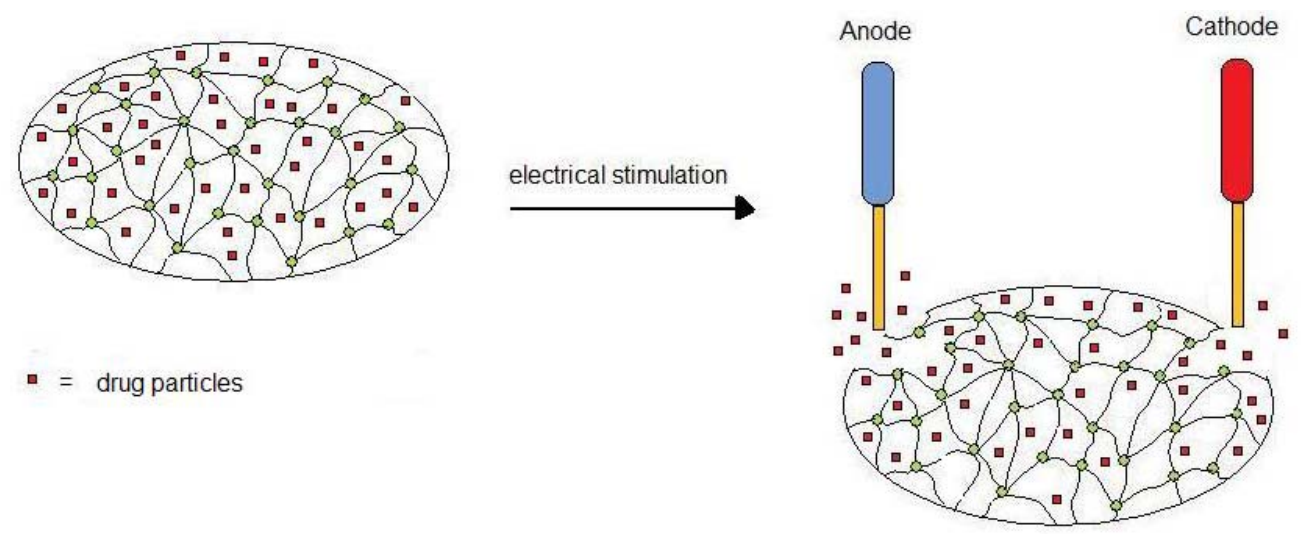

Leeching of the drug out of the

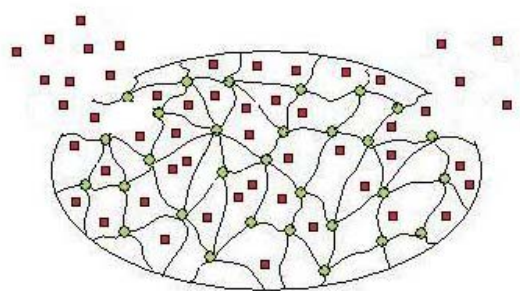


The fate of the eroded materials from the ECH may hopefully result in disintegration via breakdown from macrophages around the ECH. This mechanism of breakdown may be similar to that used in laser tattoo removal. In a modern day laser tattoo removal, the laser directs the energy towards the ink in the skin. This results in fragmentation of the ink particles into tiny pieces. These tiny pieces of broken-down ink particles are thus cleared up by the scavenging cell of the human body. Since the eroded materials from the ECH do not enter the blood stream, it is hoped that scavenging cells around the ECH may assist in removal of the eroded materials. This theory may, however, only be confirmed with future in vivo studies following histological examination of local tissue samples at the implantation site. The absence of any eroded materials at and around the implantation site would support this theory or vice versa.

\subsection{Cyclic Voltammetry Studies on the Electro-Conductive Hydrogel}

Cyclic voltammetry was performed on the $\mathrm{ECH}$ in order to assess its electro-activity. Cyclic voltammetry demonstrated the presence of two reduction and two oxidation waves as illustrated in the voltammogram shown in Figure 7. The range of the scan was between $-2 \mathrm{~V}$ to $+2 \mathrm{~V}$ with a scan rate of $100 \mathrm{mV} / \mathrm{sec}$.

Figure 7. Voltammogram showing the electro-activity of the $\mathrm{ECH}$ formulation in a range between $-2 \mathrm{~V}$ to $+2 \mathrm{~V}$.

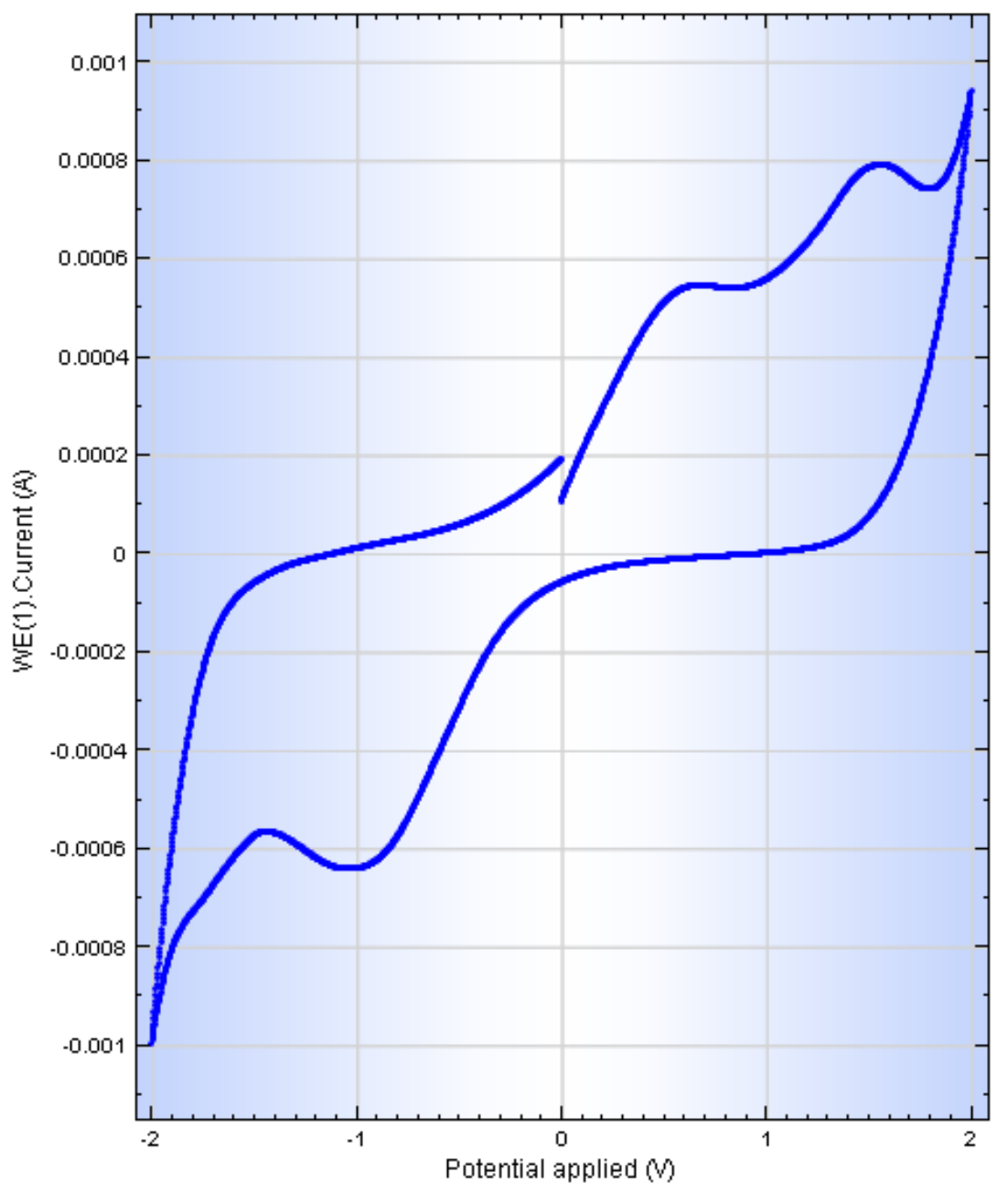


Cyclic voltammetry (CV) confirmed the presence of a charge capacity (area under CV curve) for the $\mathrm{ECH}$. The curve also indicated the presence of an intrinsic redox reaction between the electrode and the $\mathrm{ECH}$, at the potential applied between $+2 \mathrm{~V}$ and $-2 \mathrm{~V}$, resulting in an ion exchange between the electrodes and the electrolytes in the solvents carrying the mobile charged carriers to and from the ECH. Under normal circumstances, PANi exhibits two pairs of redox peaks, one at $350 \mathrm{mV}$ and the other at $800 \mathrm{mV}$ [22]. Although, the voltammogram depicted in Figure 7 also exhibited two pairs of redox waves it was reflected by a peak shift to the right. These redox potential shifts or changes may be due to more intricate reactions occurring between the PANi, the hydrogel matrix, the electrolytes and the electrode. Results deduced from Figure 5 indicated oxidation peaks occuring at approximately $0.6 \mathrm{~V}$ and $1.4 \mathrm{~V}$ and reduction peaks occuring in the region of $+1.5 \mathrm{~V}$ and $-1.0 \mathrm{~V}$. Since the PANi used for the synthesis of the ECH was PANi emeraldine base, the first oxidation peak may be attributed to the transition of the first emeraldine oxidation state to the second emeraldine oxidation state. The second oxidation wave may be attributed to the transition of the second emeraldine oxidation state to the pernigraniline oxidation state [51]. The change in the curve obtained in Figure 7 as compared to the standard voltammogram of PANi are most likely attributable to ionic interactions occuring at the various interfaces between the PANi, hydrogel matrix, electrode and the electrolyte.

\subsection{Conductivity Measurement of the ECH}

The ECH was assessed for conductivity in order to determine the role of the PANi in the ECH formulation. A conductivity meter (TDSTest ${ }^{\mathrm{TM}}$ Kit Model WD-35661-70, Oakton ${ }^{\circledR}$ Instruments, Vernon Hills, IL, U.S.) was used and ECH formulations with PANi concentrations of $1 \% \mathrm{w} / \mathrm{w}, 2.5 \% \mathrm{w} / \mathrm{w}$ and $4 \% \mathrm{w} / \mathrm{w}$ were synthesized. Six readings were obtained for each concentration and an average was recorded as summarized in Table 5. The conductivity measurement results indicated a linear increase in the conductivity of the ECH with an increase in PANi concentration.

Table 5. Conductivity data for ECH formulations containing varying PANi concentrations.

\begin{tabular}{cc}
$\begin{array}{c}\text { PANi concentration } \\
(\% \mathrm{w} / \mathrm{w})\end{array}$ & $\begin{array}{c}\text { Conductivity } \\
(\mu \mathrm{S})\end{array}$ \\
\hline 1 & $97.45 \pm 7.00$ \\
2.5 & $108.20 \pm 4.52$ \\
4 & $130.30 \pm 11.99$ \\
\hline
\end{tabular}

\subsection{Molecular Mechanics Simulations of the ECH under the Influence of an External Electric Field}

The environment surrounding the molecules of interest in molecular mechanics (MM+) was defined in terms of a solvated system to prevent artifacts that may arise from vacuum simulations and to reproduce bulk solvent properties appropriately. Although the system could also be simulated in vacuum, artifacts may be introduced in the molecular geometry which may be attributed to surface charges of the charged molecules of the ECH system interacting with each other (as opposed to interaction with the surrounding solvent in a solvated system), producing molecular conformations that are unlikely to be present in any other environment. The current system was solvated by placing explicit water molecules in the simulation box with the PVA-PANi complex and an external electric 
field in the $\mathrm{x}$-axis direction of magnitude ranging from 0.00-0.05 a.u. applied to corroborate the electro-actuable release of indomethacin from the ECH formulations under the influence of an applied potential. The computed values for the various energies of the PVA-PANi MM+ simulations under an external electric field are illustrated separately as bond, angle (torsion) and van der Waals energies in Table 6. The total steric energy of the PVA-PANi complex increased with an increase in the electric field magnitude from 0.01 a.u. to 0.05 a.u. indicating the instability caused by the applied external electric field (Figure 8). This instability was primarily induced by bond torsion $(82.93-335.47 \mathrm{kcal} / \mathrm{mol})$, stretching followed by bond angle $(44.67-141.34 \mathrm{kcal} / \mathrm{mol})$ and minimally by van der Waals interactions $(71.56-98.57 \mathrm{kcal} / \mathrm{mol})$.

Table 6. Computed energy parameters $(\mathrm{kcal} / \mathrm{mol})$ of the PVA-PANi complex in a solvated system under the influence of electric field.

\begin{tabular}{lccccc}
\hline \multirow{2}{*}{ Structure } & \multicolumn{5}{c}{ Energy $(\mathbf{k c a l} / \mathbf{m o l})$} \\
\cline { 2 - 6 } & Total & $\boldsymbol{\Delta} \mathbf{E}_{\text {stimulation }}$ & Bond & Angle & vdW \\
\cline { 2 - 6 } PVA-PANi-0.00 & $-3,115.92$ & - & 33.4948 & 56.3898 & 71.5598 \\
PVA-PANi-0.01 & $-2,826.36$ & +289.56 & 44.6791 & 82.9305 & 72.6148 \\
PVA-PANi-0.02 & $-2,643.41$ & +472.51 & 61.2286 & 129.845 & 76.1276 \\
PVA-PANi-0.03 & $-2,213.01$ & +902.91 & 86.1102 & 184.596 & 82.4647 \\
PVA-PANi-0.04 & $-1,982.23$ & $+1,133.69$ & 111.422 & 255.45 & 91.9177 \\
PVA-PANi-0.05 & $-1,772.02$ & $+1,343.9$ & 141.338 & 335.476 & 98.5723 \\
\hline \multicolumn{7}{c}{ vdW: van der Waals energy. } \\
\end{tabular}

Figure 8. Variation in total steric energy as a function of applied external electric field.

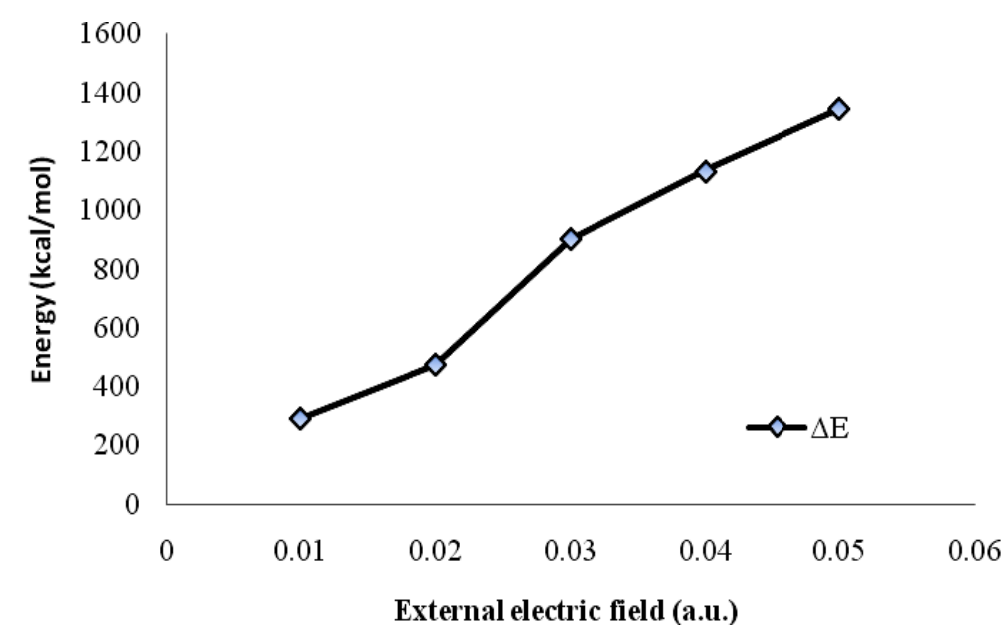

The two polymer strands (PVA and PANi) were tightly bonded in a helical model, as shown by the plausible molecular model of the complex (Figure 9). This coiled state may be responsible for the non-decomposition, non-unwinding or non-eroding of the complex on its own in solvent, as described earlier in this paper. External electric fields may change the neutral arrangement of electrons on the surface of the ECH and produce electrical forces that alter the mechanical behavior causing the adduct to form a coil rather than an extended chain resulting in the formation of a globular aniline-vinyl complex. MM+ simulations estimated the energy associated with vibration about the equilibrium bond length, and the models tended to break down as a bond was stretched toward the point of dissociation. 
Furthermore, the charge distribution affected the external electric field and produced a new net field causing the outer shell of the ECH to reach the critical concentration for erosion and subsequent flaking. The increase in energy levels of hormonic oscillators, bond and angle terms, may have resulted in instability which in turn caused complex dissociation followed by conversion of the polymers into their respective monomer units to stabilize the steric energy as the electric field was increased in magnitude (Figure 5). These findings are in line with earlier reported electro-simulation studies by Li et al., 2007, whereby they deduced that electric-stimulus-responsive hydrogels undergo a linear increase in deformation during electric-stimulation when the applied electric field is increased [1]. These energy variations and subsequent erosion can be quantified in terms of the quantity of indomethacin released after the respective applied electric potential as discussed earlier in this paper. However, as opposed to the current theory in which drug movement in and out of the hydrogel is controlled by osmotic pressure, the molecular modeling suggests that drug release from the $\mathrm{ECH}$ is primarily due to drug liberation resulting from the uncoiling of the original coiled helix structure of the ECH. However, the erosion suggests similarity to the Donnan theory, whereby the ionic interchange phenomenon occurs primarily at the surface of the $\mathrm{ECH}$, while the center exhibits limited ion exchange. In addition, because the $\mathrm{ECH}$ was formulated in a hollow cylindrical structure as opposed to a rod, this eliminates the build-up of any osmotic pressure in the centre of the $\mathrm{ECH}$ as suggested by De and Aluru [52]. This would further ensure that the drug release mechanism is primarily attributed to the uncoiling mechanism as opposed to osmotic pressure build-up.

Figure 9. Visualization of geometrical preferences of the PVA-PANi molecule after molecular simulation in a solvated system under an external electric field: (a) No external field, (b) 0.01 a.u, (c) 0.02 a.u, (d) 0.03 a.u, (e) 0.04 a.u and (f) 0.05 a.u.

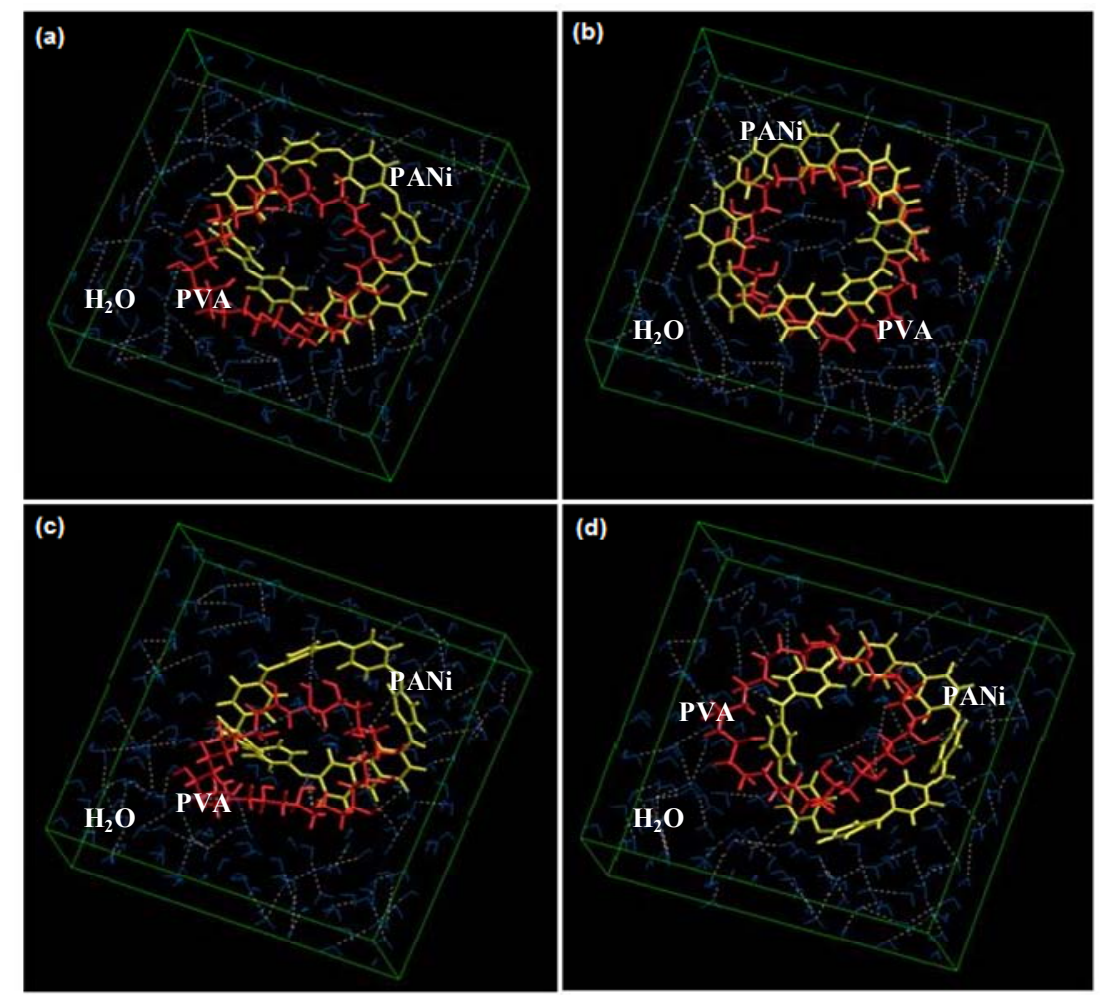


Figure 9. Cont.
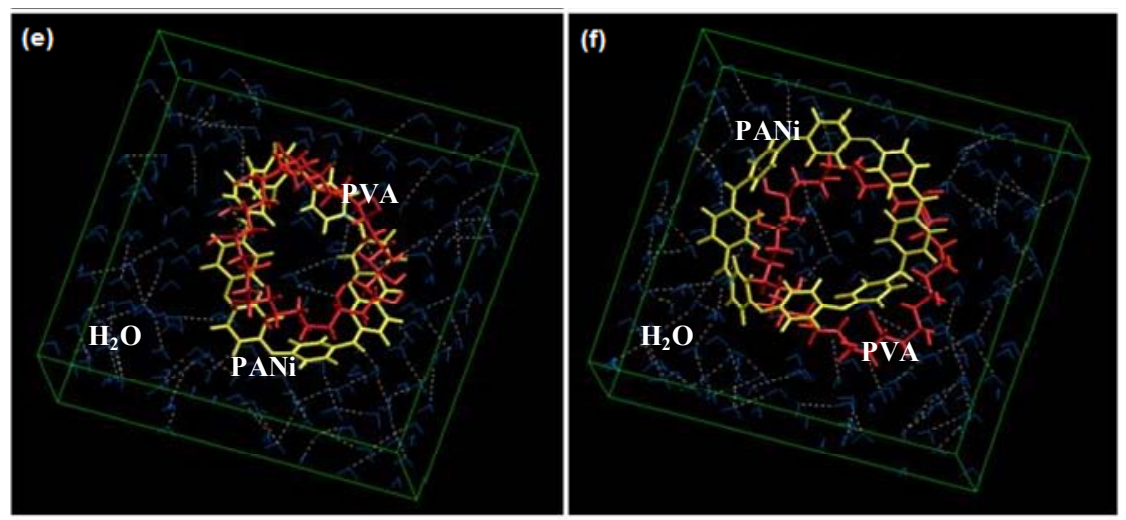

\section{Experimental Section}

\subsection{Materials}

Diethyl acetamidomalonate (DAA) was purchased from Fluka Chemie AG, Buchs, Switzerland. The commercially available polymers, polyvinyl alcohol (PVA) (Sigma-Aldrich, Steinhelm, Germany; MW = 89,000-98,000 g/mol) and polyaniline (PANi) (Sigma-Aldrich, Steinhelm, Germany; $\mathrm{MW}=20,000 \mathrm{~g} / \mathrm{mol}$ ) were used. Indomethacin was procured from Sigma-Aldrich (St Louis, MO, U.S.). Double deionized water was obtained from a Milli-Q water purification system (Milli-Q, Millipore, Billerica, MA, U.S.). All other reagents used were of analytical grade and were employed as purchased.

\subsection{Preparation of the Electro-Conductive Hydrogel}

The ECH formulations were synthesized by crosslinking PVA with DAA, thus entrapping indomethacin and the EAP within the hydrogel matrix. Initially, $0.8 \mathrm{~g}$ of PVA was dissolved in $10 \mathrm{~mL}$ of double deionized water while $0.0689 \mathrm{~g}$ of DAA and 100mg indomethacin were dissolved in acetone in separately. After the DAA and the indomethacin were completely dissolved, $1.3418 \% \mathrm{w} / \mathrm{w}$ PANi was added to the mixture. The two solutions were then blended and agitated with a glass rod in order to facilitate the crosslinking process. Crosslinking occurred spontaneously and was complete within one minute. The crosslinked polymer composite was then rinsed with distilled water and air-dried for 24 hours at room temperature.

\subsection{Optimization Studies Employing a Box-Behnken Experimental Design Template}

In order to produce an optimized $\mathrm{ECH}$ with high drug entrapment and minimum erosion, $15 \mathrm{ECH}$ formulations with various combinations of the independent variables were synthesized and tested for their drug releasing ability, drug entrapment efficiency and rate of erosion (Table 1). The results were guided through a 3-factor, 3 centre points Box-Behnken quadratic design employing Minitab Statistical Software, V15 (Minitab Inc., State College, PA, U.S.). The three independent variables employed for 
the synthesis of the ECH included the hydrogel component formed by PVA, the crosslinker DAA used to increase the structural integrity of the hydrogel and the EAP, namely PANi, to enhance the conductivity of the ECH. Table 1 represents the upper and lower limits for each of the variables. The limits for these variables were based on their ability to form a stable ECH with optimal drug release kinetics (maximum quantity of drug released before depletion) with a minimal erosion rate and maximum drug entrapment efficiency.

\subsection{Determination of the Surface Morphology of the Electro-Conductive Hydrogel}

An assessment of the surface morphology facilitated the determination of the extent of erosion on the ECH. Surface morphology was assessed using light microscopy (Olympus SZX7 ILLD2-200, Olympus, Tokyo, Japan) and scanning electron microscopy (SEM) (Phenom ${ }^{\mathrm{TM}}$, FEI Company, Hillsboro, Oregon, U.S.).

\subsection{Assessment of the Drug Release from the Electro-Conductive Hydrogel}

In order to assess the drug release from the $\mathrm{ECH}$, the system was subjected to electrical stimulation while immersed in phosphate-buffered saline (PBS; $\mathrm{pH} 7.4 ; 37^{\circ} \mathrm{C}$ ). This was performed by immersing the $\mathrm{ECH}$ in $20 \mathrm{~mL}$ of PBS and allowing a potential difference of $1.2 \mathrm{~V}$ to be maintained between the two electrodes. Platinum was used as the cathode and gold as the anode. The setup of the experiment is depicted in Figure 10.

Figure 10. Pictorial showing the experimental setup for assessing the drug release behavior from the ECH system.

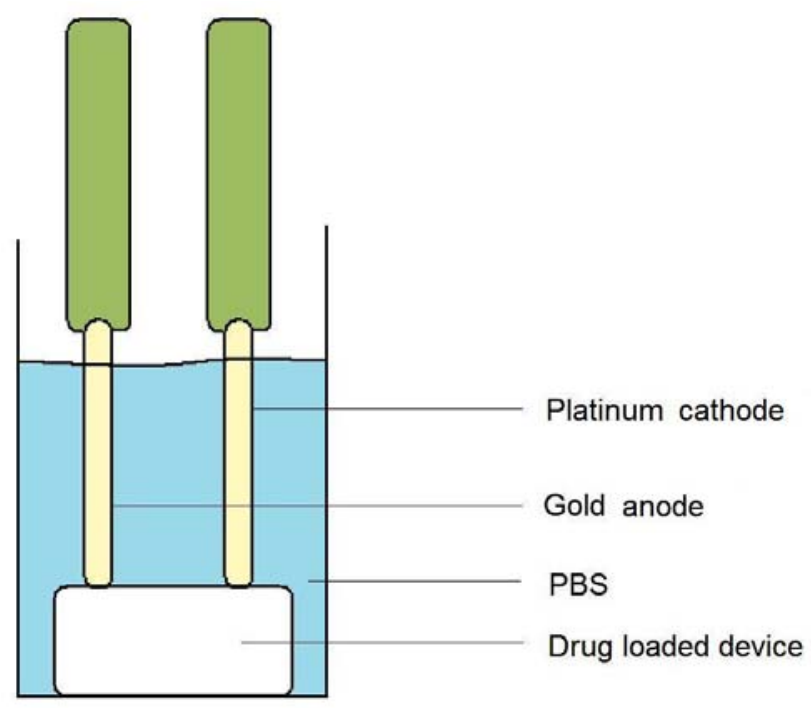

Electrical stimulation was maintained for a duration of 60 seconds before $2 \mathrm{~mL}$ samples were withdrawn for analysis of drug concentration. This was repeated four times, after which the samples were then analyzed by UV/visible spectroscopy (Lambda $25 \mathrm{UV} /$ vis Spectroscopy, Perkin-Elmer, 
Shelton, CT, U.S.) for any presence in drug via computation from a standard linear curve of indomethacin in $\mathrm{PBS}\left(\mathrm{pH} 7.4 ; 37^{\circ} \mathrm{C}\right)\left(\mathrm{R}^{2}=0.99\right)$.

\subsection{Determination of the Drug Entrapment Efficiency}

Drug Entrapment Efficiency (DEE) studies were performed on the ECH by initially removing a section of the ECH. The removed section was accurately weighed and completely dissolved in $100 \mathrm{~mL}$ of PBS. The PBS solution was then analyzed at $\lambda_{318 \mathrm{~nm}}$ for indomethacin content using a standard linear curve $[53,54]$. Equation 1 was used to compute the DEE.

$$
D E E \%=\frac{I_{a}}{I_{t}} \times 100
$$

Where, DEE\% is the drug entrapment efficiency, $I_{a}$ is the actual quantity $(\mathrm{mg})$ of indomethacin as determined by the UV/visible spectroscopy and $I_{t}$ is the theoretical quantity $(\mathrm{mg})$ of indomethacin which was added into the ECH.

\subsection{Determination of the Erosion Rate}

The rate of erosion was determined by accurately weighing the ECH prior to exposure to electrical stimulation in the fully dehydrated state. After the mass of the ECH was determined the system was hydrated and actuated via electrical stimulation for four release cycles. The ECH was then allowed to air-dry at room temperature for 48 hours in order to facilitate the removal of water from the ECH system. The ECH which was air-dried in this fashion was then re-weighed and the difference in mass was recorded. The rate of erosion was expressed by Equation 2.

$$
\mathrm{ER} \%=\frac{W o-W e}{W o} \times 100
$$

Where, ER\% represents the rate of erosion expressed as a percentage of the original weight, $\mathrm{W}_{\mathrm{o}}$ is the weight $(\mathrm{g})$ of the non-eroded $\mathrm{ECH}$ and $\mathrm{W}_{\mathrm{e}}$ is the weight $(\mathrm{g})$ of the eroded $\mathrm{ECH}$.

\subsection{The influence of Varying Concentration of Polyaniline on the Electro-Conductive Hydrogel}

In order to assess the effects of polyaniline (PANi) concentration on the erosion rate of the $\mathrm{ECH}$, two separate ECH formulations were prepared, each comprising $0.8 \mathrm{~g}$ of PVA, $0.0689 \mathrm{~g}$ of DAA and $100 \mathrm{mg}$ of indomethacin. The only difference was that the first $\mathrm{ECH}$ formulation constituted $1 \% \mathrm{w} / \mathrm{w}$ PANi while the second constituted $3 \% \mathrm{w} / \mathrm{w}$ PANi. The two formulations were then immersed in $20 \mathrm{~mL}$ PBS and a potential difference of $1.2 \mathrm{~V}$ was applied for 400 seconds in order to assess the influence of PANi on the extent of matrix erosion.

\subsection{Cyclic Voltammetry Studies on the Electro-Conductive Hydrogel}

Cyclic voltammetry was performed on the ECH in order to assess its electro-activity. PBS (pH 7.4) was employed as the conducting solvent [55-57]. Firstly, the ECH were homogenized into the PBS for 
a period of 5 minutes followed by ultrasonication (Vibra-Cell ${ }^{\mathrm{TM}}$, Sonics ${ }^{\circledR}$ Sonics \& Material Inc., Newtown, CT, U.S.) at an amplitude of $70 \%$ for a period of 3 minutes. The resultant solution was then purged with nitrogen gas for 3 minutes prior to cyclic voltammetry using a conventional three-electrode system (PGSTAT302N, Autolab, Utrecht, Netherlands) with a saturate Ag/AgCl $(3.0 \mathrm{M} \mathrm{KCl})$ as the reference electrode, a platinum wire as the auxiliary electrode and a $5 \mathrm{~mm}$ glassy carbon electrode as the working electrode [58]. The scan rate was $0.1 \mathrm{~V} /$ second.

\subsection{Molecular Mechanics Simulations}

Molecular mechanics (MM) simulations for the solvated system with water as the surrounding fluid were performed using HyperChem ${ }^{\mathrm{TM}}$ 8.0.8 Molecular Modeling software (Hypercube Inc., Gainesville, FL, U.S.) and ChemBio3D Ultra 11.0 (CambridgeSoft Corporation, Cambridge, U.K.). The octamer of polyaniline (PANi) and hexadecamer of polyvinyl alcohol (PVA) was generated from standard bond lengths and angles employing the Polymer Builder tool using ChemBio3D Ultra in their syndiotactic stereochemistry as a 3D model. The individual polymer models were initially energy-minimized using MM+ Force Field and the resulting structures were once more energy-minimized using the Amber 3 (Assisted Model Building and Energy Refinements) Force Field. The conformers having the lowest energy were used to create the polymer-polymer complexes (PVA-PANi). All MM simulations were performed under the influence of an external electric field ranging from $0.00-0.05$ a.u. for cubic periodic boxes with dimensions of $25 \times 12 \times 25 \AA^{3}$ containing one centered PVA-PANi complex with the centre of the cubic box and the remaining free-space filled with water molecules. The same procedure of energy-minimization was repeated to generate the final models: PVA-PANi-0.01 to PVA-PANi-0.05. Full geometrical optimizations were performed for the solvated system employing the Polak-Ribiere Conjugate Gradient method until a Root Mean Square (RMS) gradient of $0.001 \mathrm{kcal} / \mathrm{mol}$ was reached. Force Field options in the AMBER (with explicit solvent) were extended to incorporate limits to inner and outer options with the nearest-image periodic boundary conditions. The outer limit was set to $6.46 \AA$ and the inner was at $2.46 \AA$ to ensure that there were no discontinuities in the potential surface.

\section{Conclusions}

Results from this study concluded that PANi may be incorporated into a hydrogel matrix system in order to impart enhanced conductive capabilities for electo-actuable drug release as an ECH. This study has also shown that incorporation of the model indomethacin into the ECH controlled drug release was obtainable by electrically stimulating the $\mathrm{ECH}$, thus achieving "ON-OFF" drug release kinetics. The conductivity of the ECH increased linearly with an increase in the PANi concentration. The mechanism of indomethacin release was attributed to erosion of the $\mathrm{ECH}$ upon exposure to electrical actuation with other mechanisms, such as drug molecule migration toward the electrode. In addition, the concept of merging the experimental and theoretical investigations on the electro-actuable release of indomethacin from the ECH as applied in this study, corroborated key findings that the experimentally observable erosion and drug release could be predicted by the computational methodology employed to predict the interaction mechanisms of drug release from the electro-actuable 
ECH system. Most stimuli-responsive hydrogels, such as temperature or $\mathrm{pH}$ responsive hydrogels, rely primarily on swelling/de-swelling mechanisms and osmotic pressure in order to control movement of substances in and out of the hydrogel. The use of responsive erosion as a mechanism of controlled drug liberation as opposed to swelling/de-swelling may prove to hold great potential in the field of stimuli-responsive hydrogels.

\section{Acknowledgements}

This research is supported by the National Research Foundation (NRF) of South Africa and the Faculty Research Committee, University of the Witwatersrand, Johannesburg, South Africa.

\section{References}

1. Li, H.; Luo, R.; Lam, K.Y. Modeling of ionic transport in electric-stimulus-responsive hydrogels. J. Membr. Sci. 2007, 289, 284-296.

2. El-Sherbiny, I.M.; Abdel-Bary, E.M.; Harding, D.R.K. Preparation and in vitro evaluation of new $\mathrm{pH}$-sensitive hydrogel beads for oral delivery of protein drugs. J. Appl. Polym. Sci. 2009, 115, 2828-2837.

3. Chen, G.; Imanishi, Y.; Ito, Y. pH-sensitive thin hydrogel microfabricated by photolithography. Langmuir 1998, 14, 6610-6612.

4. Santos, J.R.; Alves, N.M.; Mano, J.F. New thermo-responsive hydrogel based on poly(N-isopropylacrylamide)/Hyaluronic acid semi-interpenetrated networks: Swelling properties and drug release studies. J. Bioact. Compat. Polym. 2010, 25, 169-184.

5. Hou, H.; Kim, W.; Grunlan, M.; Han, A. A thermal responsive hydrogel poly(N-isopropylacrylamide) micropatterning method using microfluidic technique. J. Micromech. Microeng. 2009, 19, 1-6.

6. McDonald, T.O.; Qu, H.; Saunders, B.R.; Ulijn, R.V. Branched peptide actuators for enzyme responsive hydrogel particles. Soft Matter 2009, 5, 1728-1734.

7. Thornton, P.D.; Mart, R.J.; Ulijn, R.V. Enzyme-responsive polymer hydrogel particles for controlled release. Adv. Mater. 2006, 19, 1252-1256.

8. Luiz, L.M.; de Torresi, S.I.C. Conducting polymer-hydrogel composites for electrochemical release devices: Synthesis and characterization of semi-interpenetrating polyaniline-polyacrylamide networks. Electrochem. Commun. 2005, 7, 717-723.

9. Iseki, M.; Ikematsu, M.; Sugiyama, Y.; Tago, I.; Mizukami, A. A new type of current oscillation in polypyrrole membranes produced by electrochemical potential control. J. Electroanal. Chem. 1995, 386, 253-256.

10. Geetha, S.; Rao, C.R.K.; Vijayan, M.; Trivedi, D.C. Biosensing and drug delivery by polypyrrole. Anal. Chim. Acta 2006, 568, 119-125.

11. Posadas, D.; Florit, M.I. The redox switching of electroactive polymers. J. Phys. Chem. B 2004, 108, 15470-15476.

12. Small, C.J.; Too, C.O.; Wallace, G.G. Responsive conducting polymer-hydrogel composite. Polym. Gels Netw. 1997, 5, 251-265. 
13. Richardson-Burns, S.; Hendricks, J.L.; Foster, B.; Povlich, L.K.; Kim, D.; Martin, D.C. Polymerization of the conducting polymer poly(3,4-ethylenedioxythiophene) (PEDOT) around living neural cells. Biomaterials 2007, 28, 1539-1552.

14. Kinlen, P.J.; Frushour, B.G.; Ding, Y.; Menon, V. Synthesis and characterization of organically soluble polyaniline and polyaniline block copolymer. Synth. Met. 1999, 101, 758-761.

15. Kaneto, K.; Kaneko, M.; Min, Y.; MacDiarmid, A.G. "Artificial Muscle”: Electromechanical actuators using polyaniline films. Synth. Mater. 1995, 71, 2211-2212.

16. Spinks, G.M.; Mottaghitalab, V.; Bahrami-Samani, M.; Whitten, P.G.; Wallace, G.G. Carbon-Nanotube-Reinforced Polyaniline Fibres for high-strength artificial muscle. Adv. Mater. 2006, 18, 637-640.

17. Rodrigues, M.A.; De Peoli, M.-A. Electrochemical properties of chemically prepared poly(aniline). Synth. Met. 1991, 43, 2957-2962.

18. Ćirić-Marjanović, G.; Dragičević, L.; Milojević, M.; Mojović, M.; Mentus, S.; Dojčinović, B.; Marjanović, B.; Stejskal, J. Synthesis and characterization of self-assembled polyaniline nanotubes/silica nanocomposites. J. Phys. Chem. 2009, 113, 7116-7127.

19. Wallace, G.G.; Smyth, M.; Zhao, H. Conducting electroactive polymer-based biosensors. Trends Anal. Chem. 1999, 18, 245-251.

20. Park, Y.H.; Park, C.R. Preparation of conducting polyacrylonitrile/polyaniline composite films by electrochemical synthesis and their electroactivity. Synth. Met. 2001, 118, 187-192.

21. Jayanty, S.; Prasad, G.K.; Sreedhar, B.; Radhakrishnan, T.P. Polyelectrolyte templated polyaniline-film morphology and conductivity. Polymer 2003, 44, 7265-7270.

22. Wang, C.H.; Dong, Y.Q.; Sengothi, K.; Tan, K.L.; Kang, E.T. In-vivo tissue response to polyaniline. Synth. Met. 1999, 102, 1313-1314.

23. Kamalesh, S. Tan, P.; Wang, J.; Lee, T.; Kang, E.; Wang, C. Biocompatibility of electroactive polymer in tissues. J. Biomed. Mater. Res. A 2000, 52, 467-478.

24. Bidez, P.R.; Li, S.; MacDiarmid, A.G.; Venancio, E.C.; Wei, Y.; Lelkes, P.I. Polyaniline, an electroactive polymer, supports adhesion and proliferation of cardiac myoblasts. J. Biomater. Sci. Polym. Ed. 2006, 17, 199-212.

25. Schmidt, C.E.; Venkatram, R.S.; Vacanti, J.; Langer, R. Stimulation of neurite outgrowth using an electrically conducting polymer. Proc. Natl. Acad. Sci. 1997, 94, 8948-8953.

26. Brahim, S.; Guiseppi-Elie, A. Electroconductive hydrogels: Electrical and electrochemical properties of polypyrrole-poly(HEMA) composite. Electroanalysis 2004, 17, 556-570.

27. Davis, K.A.; Anseth, K.S. Controlled release from crosslinked degradable networks. Crit. Rev. Drug Carr. Sys. 2002, 19, 385-423.

28. Chien-Chi, L.; Andrew, T.M. Hydrogels in controlled release formulation network design and mathematical modeling. Adv. Drug Delivery Rev. 2006, 58, 1379-1408.

29. Bajpai, A.K.; Shukla, S.K.; Bhanu, S.; Kankane, S. Responsive polymers in controlled drug delivery. Prog. Polym. Sci. 2008, 33, 1088-1118.

30. Kim, B.C.; Spinks, G.M.; Wallace, G.G.; John, R. Electroformation of conducting polymers in a hydrogel support matrix. Polymer 2000, 41, 1783-1790.

31. Prabaharan, M.; Mano, J.F. Stimuli-responsive hydrogels based on polysaccharides incorporated with thermo-responsive polymers as novel biomaterial. Macromol. Biosci. 2006, 6, 991-1008. 
32. Collett, J.; Crawford, A.; Hatton, P.V.; Geoghegan, M.; Rimmer, S. Thermally responsive polymeric hydrogel brushes: Synthesis, physical properties and the use for the culture of chondrocytes. J. Roy. Soc. Interface 2007, 4, 117-126.

33. Zhang, J.; Yuan, K.; Wang, Y.; Zhang, S.;Zhang, J. Preparation and pH responsive behavior of poly(vinyl alcohol)-chitosan-poly(acrylic acid) full IPN hydrogels. J. Bioact. Compat. Polym. 2007, 22, 207-218.

34. Kim, S.J.; Lee, Y.M.; Kim, I.Y.; Kim, S.I. Electrical/pH sensitive swelling behavior of polyelectrolyte hydrogels prepared with hyaluronic acid-poly(vinyl alcohol) interpenetrating polymer networks. React. Funct. Polym. 2003, 55, 291-298.

35. Kokotos, G.; Martin, V.; Constantinou-Kokotou, V.; Gibbons, W.A. Synthesis of medicinally useful lipidca-amino acids, 2 amino alcohols and diamines. Amino Acids 1996, 11, 329-343.

36. Kotha, S.; Singh, K. N-alkylation of diethyl acetamidomalonate: synthesis of constrained amino acid derivatives by ring-closing metathesis. Tetrahedron Lett. 2004, 45, 9607-9610.

37. Pawed, S.M.; Deshmukh, K. Characterization of poly vinyl alcohol/gelatin blend hydrogel films for biomedical applications. J. Appl. Polym. Sci. 2008, 109, 3431-3437.

38. Henderson, K.J.; Zhou, T.C.; Otim, K.J.; Shull, K.R. Ionically crosslinked tri-block copolymer hydrogels with high strength. Macromolecules 2010, 43, 6193-6201.

39. Sui, K.; Gao, S.; Wu, W.; Xia, Y. Injectable supermolecular hybrid hydrogels formed by MWNT-grafted-poly ethylene glycol and $\alpha$-cyclodextrin. J. Polym. Sci. A Polym. Chem. 2010, 48, 3145-3151.

40. Kulkarni, R.V.; Sa, B. Electroresponsive polyacrylamide-grafted-xanthan hydrogels for drug delivery. J. Bioact. Compat. Polym. 2009, 24, 368-384.

41. Prashantha, K.V. IPNs based on polyol modified castor oil polyurethane and poly(HEMA): Synthesis, chemical, mechanical and thermal properties. Bull. Mater. Sci. 2001, 24, 535-538.

42. L̈̈, S.; Liu, M.; Ni, B.; Gao, C. A novel pH- and thermo-sensitive PVP/CMC semi-IPN hydrogel: Swelling, phase behavior, and drug release study. J. Polym. Sci. B Polym. Phys. 2010, 48, 1749-1756.

43. You, J.; Auguste, D.T. Conductive, physiologically responsive hydrogels. Langmuir 2010, 26, 4607-4612.

44. Gürsoy, A.; Eroğlu, L.; Ulutin, S.; Taşyürek, M.; Fessi, H.; Puisieux, P.; Devissaguet, J. Evaluation of indomethacin nanocapsules for their physical stability and inhibitory activity on inflammation and platelet aggregation. Int. J. Pharm. 1989, 52, 101-108.

45. Chao, D.; Ma, X.; Lu, X.; Cui, L.; Mao, H.; Zhang, W.; Wei, Y. Design, synthesis and characterization of novel electroactive polyamide with amine-capped aniline pentamer in the main chain via oxidative coupling polymerization. J. Appl. Polym. Sci. 2007, 104, 1603-1608.

46. De La Lastra, A.C.; Motilva, V.; Martin, M.J.; Nieto, A.; Barranco, M.D.; Cabeza, J.; Herrerias, J.M. Protective effect of melatonin on indomethacin-induced gastric injury in rat. $J$. Pineal Res. 1999, 26, 101-107.

47. Couppé, C.; Hansen, P.; Kongsgaard, M.; Kovanen, V.; Suetta, C.; Aagaard, P.; Kjær, M.; Magnusson, S.P. Mechanical properties and collagen cross-linking of the patellar tendon in old and young men. J. Appl. Physiol. 2009, 107, 880-886. 
48. Emerson, D.; Ghiorse, W.C. Role of disulfide bonds in maintaining the structural integrity of the sheath of Leptothrix discophora SP-6. J. Bacteriol. 1993, 175, 7819-7827.

49. Badenhorst, D.; Maseko, M.; Tsotetsi, O.J.; Naidoo, A.; Brooksbank, R.; Norton, G.R.; Woodiwiss, A.J. Cross-linking influences the impact of quantitative changes in myocardial collagen on cardiac stiffness and remodeling in hypertension in rats. Cardiovasc. Res. 2002, 57, 632-641.

50. Rokhade, A.P.; Patil, S.A.; Aminabhavi, T.M. Synthesis and characterization of semi-interpenetrating polymer network microsphere of acrylamide grafted dextran and chitosan for controlled release of acyclovir. Carbohydr. Polym. 2007, 67, 605-613.

51. Chao, D.; Lu, X.; Chen, J.; Liu, X.; Zhang, W.; Wei, Y. Synthesis and characterization of electroactive polyamide with amine-capped aniline pentamer and ferrocene in the main chain by oxidative coupling polymerization. Polymer 2006, 47, 2643-2648.

52. De, S.K.; Aluru, N.R. A chemo-electro-mechanical mathematical model for simulation of $\mathrm{pH}$ sensitive hydrogels. Mech. Mater. 2004, 36, 395-410.

53. Zhang, H.; Zhao, J.; Liu, H.; Wang, H.; Liu, R.; Liu, J. Application of poly(3-methylthiophene) modified glassy carbon electrode as riboflavin sensor. Int. J. Electrochem. Sci. 2010, 5, 295-301.

54. Hegde, R.N.; Kumara Swamy, B.E.; Sherigara, B.S.; Nandibewoor, S.T. Electro-oxidation of atenolol at a glassy carbon electrode. Int. J. Electrochem. Sci. 2008, 3, 302-314.

55. Manjunatha, J.G.; Kumara Swamy, B.E.; Mamatha, G.P.; Chandra, U.; Niranjana, E.; Sherigara, B.S. Cyclic voltammetry studies of dopamine at lamotrigine and TX-100 modified carbon paste electrode. Int. J. Electrochem. Sci. 2009, 4, 187-196.

56. Raoof, J.; Ojani, R.; Nematollahi, D.; Kiani, A. Digital simulation of the cyclic voltammetry study of the catechols electrooxidation in the presence of some nitrogen and carbon nucleophiles. Int. J. Electrochem. Sci. 2009, 4, 810-819.

57. Zeng, Y.N.; Zheng, N.; Osborne, P.G.; Li, Y.Z.; Chang, W.B.; Wang, Z.M. Preparation and cyclic voltammetry characterization of Cu-dipyridyl imprinted polymer. Chin. Chem. Lett. 2002, 13, 317-320.

58. Le, W.; Liu, Y.; Hi, G. Preparation of manganese dioxide modified glassy carbon electrode by a novel film plating/cyclic voltammetry method for $\mathrm{H}_{2} \mathrm{O}_{2}$. J. Chil. Chem. Soc. 2009, 54, 366-371.

(C) 2011 by the authors; licensee MDPI, Basel, Switzerland. This article is an open access article distributed under the terms and conditions of the Creative Commons Attribution license (http://creativecommons.org/licenses/by/3.0/). 